\title{
Acetic Acid Influences BRL-3A Cell Lipid Metabolism via the AMPK Signalling Pathway
}

\author{
Lin Li Meilin He Hang Xiao Xiaoqian Liu Kai Wang Yuanshu Zhang
}

Key Laboratory of Animal Physiology and Biochemistry, Ministry of Agriculture, Nanjing Agricultural University, PR China

\section{Key Words}

Acetic acid $•$ AMPK Signalling pathway $\bullet$ BRL-3A cells $\bullet$ Lipid metabolism

\begin{abstract}
Background/Aims: Acetic acid (AcOH), a short-chain fatty acid, is reported to have some beneficial effects on metabolism. Therefore, the aim of this study was to investigate the regulatory mechanism of acetic acid on hepatic lipid metabolism in BRL-3A cells. Methods: We cultured and treated BRL-3A cells with different concentrations of sodium acetate (neutralized acetic acid) and BML-275 (an AMPK $\alpha$ inhibitor). The total lipid droplet area was measured by oil red $O$ staining, and the triglyceride content was determined by a triglyceride detection kit. We detected mRNA and protein levels of lipid metabolism-related signalling molecules by RT-PCR and Western blot. Results: Acetic acid treatment increased AMPK $\alpha$ phosphorylation, which subsequently increased the expression and transcriptional activity of peroxisome proliferator-activated receptor $\alpha$ and upregulated the expression of lipid oxidation genes. These changes ultimate led to increasing levels of lipid oxidation in BRL-3A cells. Furthermore, elevated AMPK $\alpha$ phosphorylation reduced the expression and transcriptional activity of the sterol regulatory element-binding protein $1 c$, which reduced the expression of lipogenic genes, thereby decreasing lipid biosynthesis in BRL-3A cells. Consequently, triglyceride content in acetate-treated BRL-3A cells was significantly decreased. Conclusions: These results indicate that acetic acid activates the AMPK $\alpha$ signalling pathway, leading to increased lipid oxidation and decreased lipid synthesis in BRL-3A cells, thereby reducing liver fat accumulation in vitro.

(C) 2018 The Author(s)

Published by S. Karger AG, Basel

\section{Introduction}

Obesity, a pathophysiological status of excessive body fat accumulation, is caused by an imbalance between energy intake and expenditure, leading to conditions such as impaired glucose tolerance, hypertension, and hyperlipidaemia; it also increases the risk for developing atherosclerosis $[1,2]$. The prevention and improvement of obesity are important
\end{abstract}

Yuanshu Zhang

KARGER
Key Laboratory of Animal Physiology and Biochemistry

College of Veterinary Medicine, Nanjing Agricultural University (China)

Fax +862584398669, E-Mail yszhang1962@163.com 
issues in modern society, and an effective countermeasure is urgently needed.

Vinegar is not only consumed as seasoning throughout the world but has also been used as a folk medicine since ancient times [3]. Acetic acid is a main component of vinegar with a concentration of 3-9\% for consumer use [4]. Acetic acid is a short-chain fatty acid (SCFA), which is produced by caecal and colonic fermentation stimulated by the ingestion of dietary fibre. Dietary fibre intake exerts several beneficial metabolic effects, including the reduction of the postprandial glycaemic response, plasma cholesterol and triglyceride concentrations, and fat storage. Consuming highly fermentable dietary fibre is reported to reduce serum cholesterol levels [5]. Previously, Hara et al. reported that a fibre-free diet containing SCFA also decreases serum cholesterol [6].

In addition to resulting from colonic bacterial fermentation of dietary fibre, $\mathrm{AcOH}$ is available through widely consumed dietary sources. It was recently reported that $\mathrm{AcOH}$ suppresses body fat accumulation. Several studies have demonstrated that acetic acidtreated mice exhibited lower hepatic triglyceride (TG) content and increased expression of lipid oxidation genes [7]. Furthermore, acetic acid activates hepatic AMPKo in diabetic KK$\mathrm{A}(\mathrm{y})$ mice [8].

The liver is a vital organ that regulates lipid metabolism and maintains lipid homeostasis. AMP-activated protein kinase (AMPK) acts as a "sensor" and "regulator" of energy in hepatocytes [9]. AMPK modulates hepatic lipid metabolism by regulating several lipid metabolism-related transcription factors, such as peroxisome proliferator-activated receptor $\alpha(\mathrm{PPAR} \alpha)$ and sterol regulatory element-binding protein 1c (SREBP-1c), both of which govern the expression of lipid metabolic enzymes [10,11]. Therefore, the AMPK signalling pathway plays a central role in hepatic lipid metabolism. Consequently, genes downstream of AMPK $\alpha$ that are involved in lipid oxidation are upregulated in response to AMPK $\alpha$ activation, increasing lipid oxidation. These studies demonstrated that acetic acid reduces liver fat accumulation by activating the AMPK pathway.

Despite these findings, it remains unclear whether acetic acid stimulates liver cells to affect lipid metabolism. Therefore, the objective of this study was to investigate the molecular mechanism by which acetic acid regulates lipid metabolism in rat liver cells. The results of this study provide insights into the physiological function of acetic acid in hepatic lipid metabolism at the cellular level.

\section{Materials and Methods}

\section{Cell culture}

BRL-3A rat liver cells were purchased from the cell bank of the Chinese Academy of Sciences (Kunming, China). Cells were grown in Dulbecco's modified Eagle's medium (DMEM) supplemented with 10\% foetal bovine serum, seeded in 6 -well plates at $3 \times 10^{5}$ cells $/ \mathrm{cm}^{2}$ and allowed to adhere for $2 \mathrm{~h}$ in an incubator set at $37^{\circ} \mathrm{C}$ with $5 \% \mathrm{CO}_{2}$ and $95 \%$ atmospheric air.

\section{Sodium acetate (NaAC) treatment}

Cells were serum-starved overnight followed by treatment with sodium acetate (acetate) in the form of neutralized acetic acid to avoid changing the $\mathrm{pH}$ of the medium. The BRL-3A cells were subjected to the following treatments. For time course experiments, BRL-3A cells were treated with $4 \mathrm{mM}$ of acetate for $0,1,3,6,12$ and $24 \mathrm{~h}$. For dose-response experiments, BRL-3A cells were treated with acetate and BML275 (an AMPK $\alpha$ inhibitor that inhibits AMPK $\alpha$ phosphorylation at threonine-172, purchased from Santa Cruz Biotechnology, Inc. Santa Cruz, CA). Treated BRL-3A cells were divided into a control group (0 mM of acetate), a low-dose acetate treatment group ( $2 \mathrm{mM}$ of acetate), a medium-dose acetate treatment group (4 $\mathrm{mM}$ of acetate), a high-dose acetate treatment group ( $8 \mathrm{mM}$ of acetate), a BML-275 group (10 $\mu \mathrm{M}$ of BML$275)$, and a BML-275 + acetate group (10 $\mu \mathrm{M}$ of BML-275 + $4 \mathrm{mM}$ of acetate). All groups were treated for 3 h. Each treatment concentration of acetate or BML-275 was replicated 24 times. 


\section{Cellular Physiology Cell Physiol Biochem 2018;45:2021-2030 \begin{tabular}{l|l|l} 
and Biochemistry & $\begin{array}{l}\text { DOI: 10.1159/000487980 } \\
\text { Published online: March 09, } 2018\end{array}$ & $\begin{array}{l}\text { C) } 2018 \text { The Author(s). Published by S. Karger AG, Basel } \\
\text { www.karger.com/cpb }\end{array}$
\end{tabular}}

\section{Annexin V/propidium iodine staining assay}

Cells undergoing apoptosis were identified using Annexin V-FITC and propidium iodine (PI) dual staining and measured by flow cytometry. Briefly, cells were cultured in 6 -well plates $\left(2 \times 10^{6}\right.$ cells per well $)$ and treated with $0,2,4$ or $8 \mathrm{mM}$ of acetate for $6 \mathrm{~h}$. Cells were harvested and washed with cold phosphate buffered saline and resuspended in $200 \mu \mathrm{L}$ of binding buffer. Two hundred microliters of Annexin V-FITC stock solution was added to the cells, which were then incubated for $30 \mathrm{~min}$ at $4^{\circ} \mathrm{C}$ in the dark. This was followed by further incubation with propidium iodide solution $(10 \mu \mathrm{L}$, containing RNase). Cells were then immediately detected using a FACSCalibur TM flow cytometer (Becton Dickinson, San Jose, CA, USA) to measure apoptosis. Approximately 10, 000 cells were analysed in each sample.

\section{Oil Red 0 staining}

Cells were cultured in 6 -well plates $\left(2 \times 10^{6}\right.$ cells per well $)$ and treated with $0,2,4,8 \mathrm{mM}$ of acetate, 10 $\mu \mathrm{M}$ of BML-275 or $10 \mu \mathrm{M}$ of BML-275 $+4 \mathrm{mM}$ of acetate for $6 \mathrm{~h}$. Oil Red 0 staining was performed according to previously described methods [12]. Briefly, cells were fixed with $10 \%$ buffered formalin for at least 30 min. Next, cells were incubated with $60 \%$ isopropanol for $15 \mathrm{~min}$ at room temperature and stained with Oil Red 0 solution for another 15 min. Cells were washed 4 times with deionized water and then allowed to air dry. To normalize cell number, cells were counterstained with haematoxylin for 5 min after Oil Red O staining. Slides were imaged with an optical microscope (Olympus BX53; Tokyo, Japan). Twenty photos were randomly selected from each group, and ten independent visual fields of each photo were used to analyse the count and area of lipid droplets using Image-pro Plus 6.0 software (Media Cybernetics, Silver Spring, MD, USA).

\section{Detection of triglyceride (TG) content}

BRL-3A cells were collected after incubation with NaAC and BML-275 for 6 h. Cells were disrupted with an ultrasonic processor to collect TGs, and TG content was measured using a triglyceride detection kit (Nanjing Jiancheng Bioengineering Institute, Jiancheng, Nanjing, China).

\section{Quantitative real-time RT-PCR}

Total RNA was extracted using Trizol according to manufacturer's instructions (Invitrogen Corp, Carlsbad, CA), and RNA was reverse transcribed into cDNA using a reverse transcription kit (TaKaRa Biotechnology Co., Ltd., Tokyo, Japan) according to the manufacturer's instructions. All primers were synthesized by Sangon (Sangon Biotech Co., Ltd., Shanghai, China). mRNA expression levels were evaluated by quantitative real-time polymerase chain reaction (qRT-PCR) analysis using the SYBR Green QuantiTect RT-PCR Kit (Roche, Basel, Switzerland). qRT-PCR was performed on a 7500 Real-Time PCR System (Applied Biosystems/Life Technologies, Grand Island, NY). Gene primers were designed using Primer Express software 5.0. The primer sequences are shown in Table 1. mRNA expression levels were normalized to the housekeeping gene $\beta$-actin. Real-time PCR was conducted under the following conditions: initial denaturation at $95^{\circ} \mathrm{C}$ for $3 \mathrm{~min}$, then 45 cycles of amplification (denaturation at $95^{\circ} \mathrm{C}$ for 15 $\mathrm{s}$, annealing at $60^{\circ} \mathrm{C}$ for $1 \mathrm{~min}$ ).

\section{Western blot analysis}

BRL-3A cells were treated for 5 min with lysis buffer containing $1 \%$ proteinase inhibitor. Homogenates were then centrifuged at 12, $000 \mathrm{rpm}$ for $10 \mathrm{~min}$ at $4^{\circ} \mathrm{C}$. Protein concentrations were determined using an assay kit (Bio-Rad, München, Germany). Proteins were separated on polyacrylamide gels and

Table 1. The primer sequences of the genes

\begin{tabular}{|c|c|c|}
\hline Gene & $\begin{array}{l}\text { Forward primer }\left(5^{\prime}-3^{\prime}\right) \text {; } \\
\text { Reverse primer }\left(5^{\prime}-3^{\prime}\right)\end{array}$ & Product size (bp) \\
\hline$\beta$-actin & $\begin{array}{l}\text { GCTAACAGTCCGCCTAGAAGCA } \\
\text { GTCATCACCATCGGCAATGAG }\end{array}$ & 180 \\
\hline $\mathrm{ACC} \alpha$ & $\begin{array}{l}\text { ACGCAGGCATCAGAAGATTA } \\
\text { GAGGGTTCAGTTCCAGAAAGTA }\end{array}$ & 179 \\
\hline FAS & $\begin{array}{l}\text { GCACTACCACAACCCAAACCC } \\
\text { CGTTGGAGCCACCGAAGC }\end{array}$ & 161 \\
\hline SCD-1 & $\begin{array}{l}\text { CCGCCCTGAAATGAGAGATG } \\
\text { AGGGCTCCCAAGTGTAACAGAC }\end{array}$ & 154 \\
\hline SREBP-1C & $\begin{array}{l}\text { CGACTACATCCGCTTCCTTCA } \\
\text { ACTTCCACCGCTGCTACTG }\end{array}$ & 259 \\
\hline $\operatorname{PPAR} \alpha$ & $\begin{array}{l}\text { GGAGGTCCGCATCTTCCACT } \\
\text { GCAGCAAATGATAGCAGCCACA }\end{array}$ & 352 \\
\hline CPT-1 & $\begin{array}{l}\text { CCCATGTCCTTGTAATGAGCCAG } \\
\text { AGACTTCGCTGAGCAGTGCCA }\end{array}$ & 254 \\
\hline CPT-2 & $\begin{array}{l}\text { ACGCCGTGAAGTATAACCCT } \\
\text { CCAAAAATCGCTTGTCCCTT }\end{array}$ & 119 \\
\hline L-FABP & $\begin{array}{l}\text { AAGTACCAAGTCCAGACCCAG } \\
\text { CACGATTTCCGACACCC }\end{array}$ & 111 \\
\hline ACO & $\begin{array}{l}\text { TAAGCCTTTGCCAGGTATT } \\
\text { ATGGTCCCGTAGGTCAG } \\
\text { TTGAGCATGAAGGACACGAA }\end{array}$ & 189 \\
\hline
\end{tabular}


electrotransferred onto PVDF membranes that were blocked in bovine serum albumin/TBST buffer for 2 $\mathrm{h}$ at room temperature. After blocking, membranes were hybridized overnight at $4{ }^{\circ} \mathrm{C}$ at dilutions of 1:500 per antibody in block: AMPK $\alpha$, P-AMPK $\alpha, \operatorname{ACC} \alpha, \mathrm{P}-\mathrm{ACC} \alpha$, and FAS (Cell Signaling Technology, Inc., Danvers, MA, USA); SREBP-1c and PPAR $\alpha$ (Novus, Saint Louis, Missouri); L-FABP and CPT-1 (Abcam, Cambridge, England); and histone (Bioworld technology, co. Ltd). The membrane was then washed with TBST and incubated again with secondary antibody (Protein technology, Chicago, IL). Finally, blots were washed, and the signal was detected by enhanced chemiluminescence (ECL) using the LumiGlo substrate (Super Signal West Pico Trial Kit, Pierce, USA). The ECL signal was recorded using an imaging system (Bio-Rad, USA) and analysed with Quantity One software (BioRad, USA). The relative expression levels of all proteins were normalized to $\beta$-actin and histone levels.

\section{Statistics}

All results are expressed as the means \pm standard error (SE). Statistical analysis was performed using the statistical analysis program SPSS 13.0 (SPSS, Chicago, IL). $p<$ 0.05 was considered significant.

\section{Results}

Effects of NaAC treatment duration on apoptosis in BRL-3A cells.

No significant differences were observed in apoptosis ratios in any NaAC-treated groups when compared to the control group (Fig. 1A, B; $p>$ 0.05).

Effect of NaAC on lipid droplet accumulation in BRL-3A cells.

To analyse the distribution of lipid droplets in cells after NaAC treatment, Oil Red 0 staining (Fig. 2A) was used and showed that the total area of lipid droplets was significantly decreased at 4 and $8 \mathrm{mM}$ acetatetreated groups compared to the control group (Fig. 2B; $p<$ $0.05)$. However, the total area of lipid droplets was significantly higher in the BML-275 groups than in the control group (Fig. $2 \mathrm{~B} ; p<0.05)$. In the BML-275 + acetate group, the total area of lipid droplets was significantly higher than in the medium-dose group (Fig. 2B; $p<0.05$ ).

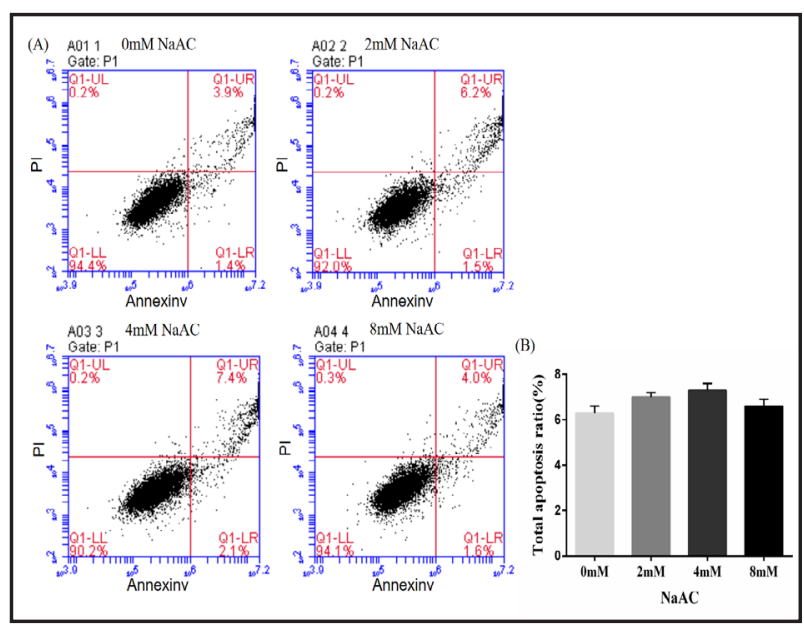

Fig. 1. Effect of acetate on apoptosis in BRL-3A cells. BRL-3A cells were treated with acetate and BML-275 and were divided into several groups: control group (0 $\mathrm{mM}$ of acetate), low-dose group ( $2 \mathrm{mM}$ of acetate), medium-dose group ( $4 \mathrm{mM}$ of acetate), and high-dose group ( $8 \mathrm{mM}$ of acetate). (A): Flow cytometry analysis of BRL-3A cells. (B): Total apoptosis ratio in BRL-3A cells. Data are presented as the means \pm SEM $(n=3)$.

Fig. 2. Representative images of hepatocytes stained with Oil Red 0 in BRL-3A cells treated with acetate. The BRL-3A cells were treated with acetate and BML-275 and were divided into several groups: control group $(0$ $\mathrm{mM}$ of acetate), lowdose group (2 mM of acetate), medium-

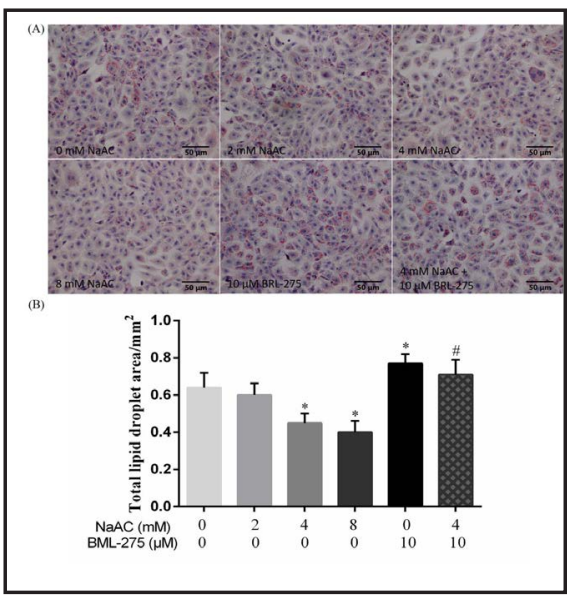
dose group (4 mM of acetate), high-dose group ( $8 \mathrm{mM}$ of acetate), BML-275 group (10 $\mu \mathrm{M}$ of BML-275), and BML-275 + acetate group (10 $\mu \mathrm{M}$ of BML$275+4 \mathrm{mM}$ of acetate). (A): Representative images of Oil Red 0 staining. (B): Total lipid droplets area. Data are presented as the means \pm SEM. ${ }^{*} \mathrm{p}<0.05$, compared to the control group; ${ }^{*}<<0.05$, compared to the medium-dose group.

\section{KARGER}


Fig. 3. TG content in BRL-3A cells. Acetate (sodium acetate) was used in the form of neutralized acetic acid to avoid changing the $\mathrm{pH}$ of the medium. Data are presented as the means \pm SEM $(n=3)$. ${ }^{*} \mathrm{p}<0.05$, compared to the control group; ${ }^{*} \mathrm{p}<0.05$, compared to the medium-dose group.

\section{TG content}

Acetate decreased BRL-3A cells TG content in a dose-dependent manner (Fig. 3). The TG content was significantly lower in the medium-dose $(4 \mathrm{mM}$ acetate) and high-dose (8 $\mathrm{mM}$ acetate) treatment group than in the control group $(p<0.05)$. However, it was significantly higher in the BML-275 groups than in the control group $(p<0.05)$. In the BML- $275+$ acetate group, the TG content were significantly higher than in the medium-dose group $(p<0.05)$.

Effects of acetate treatment duration on AMPKa phosphorylation in BRL-3A cells.

The phosphorylation levels of AMPK $\alpha$ were significantly higher in acetate-treated groups than in the control group from 1 to $6 \mathrm{~h}$ (Fig. 4A, B; $p<0.05$ ).

Effects of different concentrations of acetate on the phosphorylation of AMPK $\alpha$ in BRL-3A cells.

As shown in Fig. 5A-B, the level of AMPK $\alpha$ phosphorylation (P-AMPK $\alpha / A M P K \alpha$ ) was significantly greater in the low- and medium-dose groups than in the control group and was markedly lower in the BML-275 group than in the control group $(p<0.05)$. In the BML-275 + acetate group, the levels of AMPK $\alpha$ phosphorylation were significantly lower than in the medium-dose group $(p<0.05)$.

Expression and transcriptional activity of PPAR $\alpha$ and SREBP-1c in BRL-3A cells.

Protein levels of PPAR $\alpha$ were significantly increased in the acetate-treated groups compared with the control group and were significantly lower in the BML-275 group than in the control group. In the BML-275 + acetate group, the levels of PPAR $\alpha$ were significantly lower than in the medium-dose group (Fig. 6A, B; $p<0.05$ ).

Protein levels of SREBP-1c were significantly decreased in the medium- and high-dose groups compared to the control group and were significantly higher in the BML-275 group than in the control group. In the BML-275 + acetate group, levels of SREBP-1c were significantly higher than in the medium-dose group (Fig. 6A, C; $p<0.05$ ).

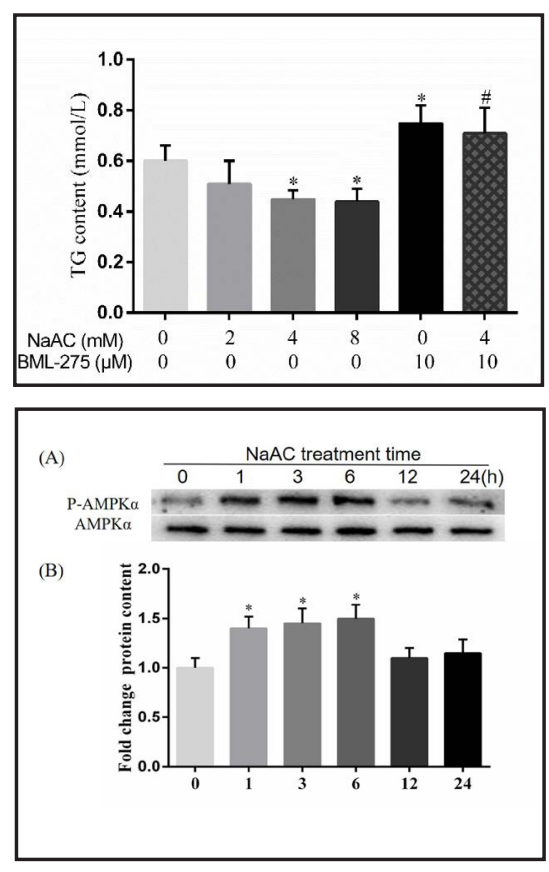

Fig. 4. Influence of acetate treatment duration on AMPK $\alpha$ phosphorylation in BRL-3A cells. BRL-3A cells were treated with $4 \mathrm{mM}$ of acetate for $0,1,3,6,12$, or $24 \mathrm{~h}$. Data are presented as the means \pm SEM. ${ }^{*} \mathrm{p}<0.05$, compared to the control group.

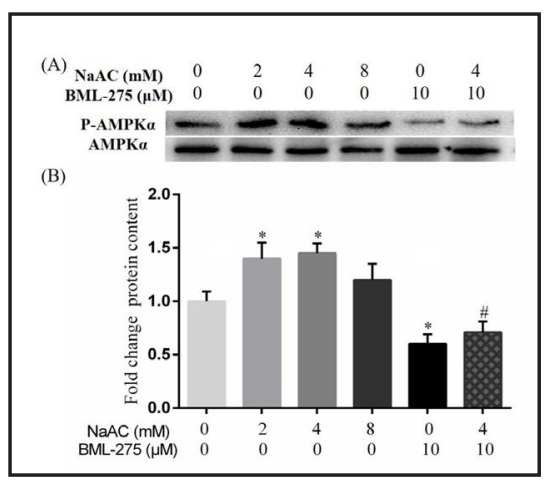

Fig. 5. Different concentrations of acetate affect phosphorylation of AMPK $\alpha$ in BRL-3A cells. (A): Western blotting results for P-AMPK $\alpha$ and AMPKo. (B): Phosphorylation levels of AMPK $\alpha$. Data are presented as the means \pm SEM $(n=6) .{ }^{*} p<0.05$, compared to the control group; ${ }^{*}<<0.05$, compared to the medium-dose group.

$m R N A$ and protein expression levels of PPAR $\alpha$ target genes in BRL-3A cells.

The mRNA levels of the PPAR $\alpha$ target genes liver fatty acid-binding protein (L-FABP), carnitine palmitoyl transferase 1 (CPT-1), carnitine palmitoyl transferase 2 (CPT-2) and acyl- 
Fig. 6. Influence of acetate and BML-275 on the protein levels of nuclear transcription factors PPAR $\alpha$ and SREBP-1c in BRL-3A cells. (A): Western blotting results for PPAR $\alpha$ and SREBP-1c. (B): Protein levels of PPAR $\alpha$. (C): Protein

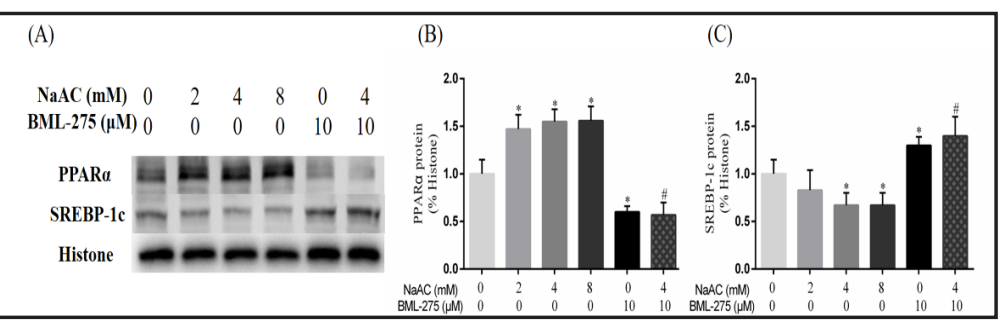
levels of SREBP-1c. Data are presented as the means \pm SEM $(n=6)$. ${ }^{*} p<0.05$, compared to the control group; ${ }^{\#} p<0.05$, compared to the medium-dose group.

Fig. 7. Effect of acetate on expression levels of L-FABP, CPT-1, CPT-2 and ACO in BRL3 A cells. (A): Western blotting results for L-FABP and CPT-1. (B-C): mRNA and protein levels of L-FABP. (D-E): mRNA and protein levels of CPT-1. (F): mRNA and protein levels of CPT-2. (G): mRNA and protein levels of ACO. Data are presented as the means $\pm \operatorname{SEM}(n=6) .{ }^{*} \mathrm{p}<0.05$, compared to the control group; ${ }^{\#} \mathrm{p}<0.05$, compared to the medium-dose group.

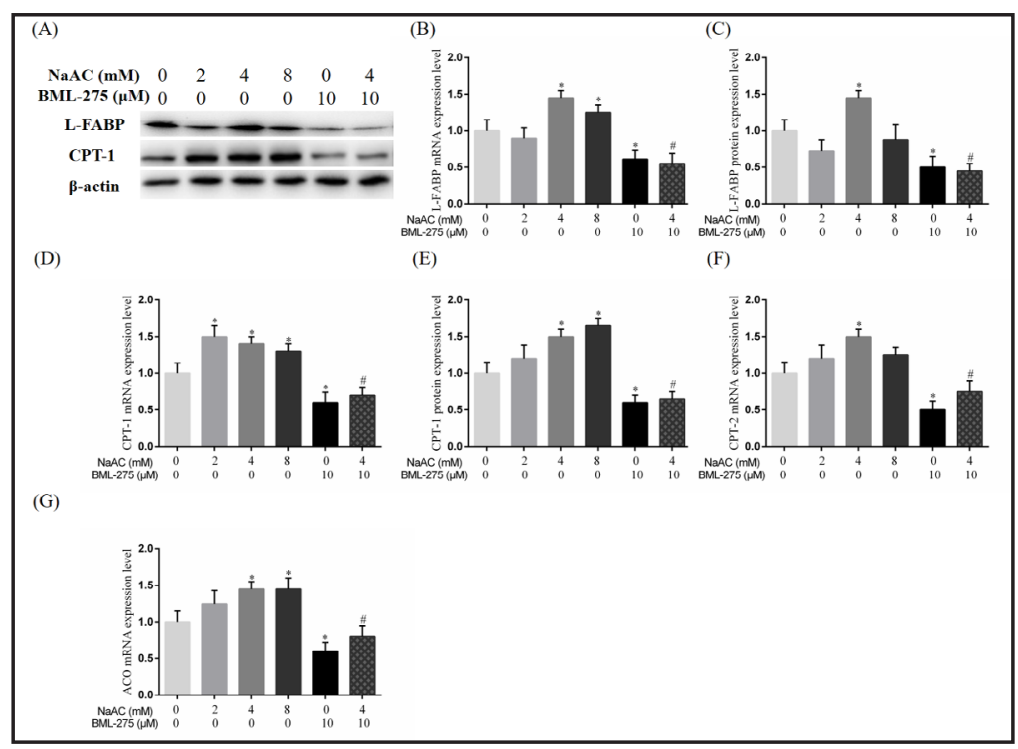

CoA oxidase (ACO) showed an increasing trend in the acetate-treated groups (Fig. 7B, D, F, $\mathrm{G} ; p<0.05)$. The mRNA levels of L-FABP and ACO were markedly higher in the medium-dose and high-dose acetate treatment groups than in the control group (Fig. 7B, G; $p<0.05$ ), and CPT-2 was significantly higher in the medium-dose group (Fig. 7F; $p<0.05$ ). In contrast, the mRNA levels of L-FABP, CPT-1, CPT-2, and ACO were all significantly lower in the BML275 group than in the control group (Fig. 7B, D, F, G; $p<0.05$ ). In the BML-275 + acetate group, the mRNA levels of L-FABP, CPT-1, CPT-2, and ACO were significantly lower than in the medium-dose group (7B, D, F, G; $p<0.05)$. L-FABP protein levels in medium-dose treatment groups were significantly increased compared to the control group and significantly lower in the BML-275 group than in the control group (Fig. 7A, C; $p<0.05$ ). In the BML-275 + acetate group, protein levels of L-FABP were significantly lower than in the medium-dose group (Fig. $7 \mathrm{~A}, \mathrm{C} ; p<0.05)$. CPT-1 protein levels in the medium- and high-dose groups were significantly increased compared to the control group and were significantly lower in the BML-275 group than the control group (Fig. 7A, E; $p<0.05$ ). In the BML-275 + acetate group, the protein levels of CPT-1 were significantly lower than in the medium-dose group (Fig. 7A, E; $p<0.05$ ).

mRNA and protein expression levels of SREBP-1c target genes in BRL-3A cells.

The mRNA expression levels of the SREBP-1c target genes, including acetyl-CoA carboxylase 1 (ACC $\alpha$ ), fatty acid synthase (FAS), and stearoyl-CoA desaturase-1 (SCD-1), tended to decrease in the acetate-treated groups (Fig. 8B, D, F; $p<0.05$ ). However, the mRNA levels of ACC $\alpha, F A S$, and SCD-1 were significantly higher in the BML-275 group than in the control group (Fig. 8B, D, F; $p<0.05$ ). In the BML-275 + acetate group, the mRNA levels of ACC $\alpha$, FAS, and SCD-1 were significantly higher than in the medium-dose group (Fig. 8B, D, $\mathrm{F} ; p<0.05)$. 
Phosphorylation levels of ACC $\alpha$ were significantly higher in the acetate treatment groups compared to the control group while being significantly lower in the BML-275 group than in the control group (Fig. 8A, C; $p<$ $0.05)$. In the BML-275 + acetate group, ACC $\alpha$ phosphorylation was significantly lower than in the medium-dose group (Fig. $8 \mathrm{~A}, \mathrm{C} ; p<0.05$ ).

FAS protein levels were significantly decreased in both the low- and medium-dose groups compared to the control group. In contrast, FAS was significantly higher in the BML275 group than in the control group (Fig. 8A, E; $p<0.05$ ). In the BML-275 + acetate group, protein levels of FAS were significantly higher than in the medium-dose group (Fig. 8A, E; $p$ $<0.05$ ).

Taken together, these results suggest that acetate significantly upregulates the expression of lipid oxidation genes and downregulates the expression of lipid synthesis genes in BRL-3A cells.

\section{Discussion}

In animals, the liver is the primary organ responsible for modulating lipid metabolism and maintaining lipid homeostasis through responses to nutrient signals. In recent years, studies have shown that acetic acid can act as a signalling molecule that modulates expression of lipid metabolism genes in hepatocytes [13]. Apoptosis is well suited to a role in tissue homoeostasis, since it can result in extensive deletion of cells with little tissue disruption [14]. In this study, we observed that apoptosis seems to exert little influence on acetate-treated BRL-3A cells compared to controls. By all indications, sodium acetate caused no damage to BRL-3A cells. Lipid droplet accumulation is important for evaluating overall lipid metabolic status [15]. Our results showed that acetate treatment significantly reduced the amount and total area of lipid droplets in BRL-3A cells. Furthermore, the TG content was significantly lower in the medium-dose and high-dose treatment groups than in the control group. These results are consistent with a previous report demonstrating that acetate treatment suppress fatty acid synthesis in KK-A(y) mice [8].

A previous study demonstrated acetic acid activates AMPK $\alpha$, which in turn upregulates the expression of lipid oxidation genes in the liver to reduce fat accumulation [16]. Liverspecific AMPK $\alpha$ deletion in mice leads to increased plasma TG content and hepatic lipogenesis [17]. AMPK mediates glucose uptake and free fatty acid oxidation in skeletal muscle and inhibits gluconeogenesis, glycolysis, lipogenesis, and cholesterol formation in the liver [18]. AMPK is also an important lipid metabolism regulator that affects lipid metabolism transcription factors, such as PPAR $\alpha$ and SREBP-1c [19, 20]. PPAR $\alpha$ influences intracellular lipid and carbohydrate metabolism by regulating the expression of genes involved in fatty acid transport, activation, and $\beta$-oxidation, such as L-FABP, ACSL- 1, CPT- 1, CPT- 2 and acylCoA oxidase (ACO) [21]. L-FABP regulates the intake and transport of fatty acids within cells [22]. CPT-1 is an integral outer membrane protein that converts activated fatty acids into 
acyl carnitines [23]. CPT-2 plays an essential role in the transfer of long-chain fatty acids [24]. ACO is a rate-limiting enzyme in fatty acid $\beta$ oxidation [25]. Mice that lack PPAR $\alpha$ display attenuated fatty acid $\beta$-oxidation, resulting in increased free fatty acids, as well as TG accumulation that causes fatty liver [26]. In the process of fatty acid $\beta$-oxidation, ACSL1 catalyses long-chain fatty acids to long-chain fatty acyl-CoA and plays an important role in channelling fatty acids either towards complex lipid synthesis and storage or towards oxidation [27].

In this study, we demonstrated that acetate activates AMPK $\alpha$. The expression levels and transcriptional activity of PPAR $\alpha$ were significantly increased in acetate treatment groups and were significantly lower in the BML-275 group than in the control group. Furthermore, PPAR $\alpha$ protein levels were significantly lower in the BML-275 + acetate group than in the medium-dose group. These results indicate that acetic acid-activated AMPK $\alpha$ promotes the expression and transcriptional activity of PPAR $\alpha$. Moreover, the mRNA levels of PPAR $\alpha$ target genes, including L-FABP, ACSL-1, CPT-1, and CPT-2, were in accordance with PPAR $\alpha$. CPT1 protein levels were significantly increased in the medium-dose and high-dose treatment groups and were significantly lower in the BML-275 group than in the control group. Furthermore, the protein levels of CPT-1 were also significantly lower in the BML-275 + acetate group than in the medium-dose group. However, L-FABP protein expression levels were significantly increased in the medium acetate treatment groups.

Our data demonstrated that acetate increases lipid oxidation in BRL-3A cells. Increases in PPAR $\alpha$ expression induced by acetate increased non-esterified fatty acid incomplete oxidation in BRL-3A cells.

SREBP-1c is the most important inducer of de novo hepatic lipogenesis and does so by modulating lipogenic enzymes, such as ACC $\alpha$, FAS and SCD-1 [28, 29]. Importantly, ACC $\alpha$, FAS, and SCD-1 are key rate-controlling enzymes in lipid synthesis. The synthesis of malonyl$\mathrm{CoA}$ is the first committed step of fatty acid synthesis, and the enzyme that catalyses this reaction, ACC $\alpha$, is the major regulatory site in fatty acid synthesis [30]. FAS is a determinant of the maximal capacity of the liver to synthesize fatty acids by de novo lipogenesis [31]. SCD-1 catalyses the synthesis of monounsaturated fatty acids, particularly oleate and palmitoleate, which are the major components of TG [31]. The incidence of fatty liver was decreased when silencing the expression of SREBP-1c, and its target genes FAS and ACC $\alpha$ were significantly decreased in ob/ob mice [32]. Furthermore, an in vivo study demonstrated that administration of acetic acid to rats decreased the expression of lipogenic genes, including ACC $\alpha$ and FAS. Mice that overexpress SREBP-1c exhibited a 4-fold increase in the rate of fatty acid synthesis, leading to lipid accumulation in the liver [33].

In this study, we demonstrated that the expression, binding and transcriptional activity of SREBP-1c were significantly decreased in medium-dose and high-dose acetate treatment groups compared to controls. Furthermore, nuclear translocation of SREBP-1c was significantly increased in the BML-275 group compared to the control group. Total protein levels of SREBP-1c were significantly higher in the BML-275 + acetate group than in the medium-dose group. Interestingly, the expression of downstream genes ACC $\alpha$, FAS and SCD-1 was also significantly lower in the acetate-treated groups than in the control group, while being significantly increased in the BML-275 group versus the control group. These genes were also significantly higher in the BML-275 + acetate group than in the mediumdose group. Furthermore, ACC $\alpha$ protein levels were significantly lower in acetate-treated groups than in the control group. However, FAS protein levels were only significantly lower in the low-dose and medium-dose treatment groups compared to the control group, while being significantly increased in the BML-275 group compared to both the medium-dose and control groups. Furthermore, the protein level of FAS was also significantly higher in the BML-275 + acetate group than the medium-dose group. Together with the downregulation of SREBP-1c, these data provide a molecular explanation for the well-known shift in hepatic lipid metabolism from lipid synthesis and storage to oxidation associated with high acetic acid. 
In conclusion, the current study indicates that acetic acid acts as a signalling molecule that significantly increases lipolysis and decreases lipid synthesis in BRL-3A cells. Acetate activates AMPK/PPAR $\alpha$ signalling and upregulates expressions of lipid oxidation genes, thereby increasing lipid oxidation in hepatocytes. In addition, activation of AMPK inhibits the expression, binding and transcriptional activity of SREBP-1c and decreases expression of lipid synthesis genes. Consequently, acetic acid increases lipolysis and decreases lipid synthesis in BRL-3A cells, which reduces hepatic fat accumulation in BRL-3A cells.

\section{Acknowledgements}

This work was supported by the $13^{\text {th }}$ Five-Year State Key Development Program (2017YFD0500505), the National "973" Project on Milk Composition Precursors Redistribution Mechanism and Epigenetic Mechanism in Liver (grantnumber 2011CB100802) and the Priority Academic Program Development of Jiangsu Higher Education Institutions (PAPD).

\section{Disclosure Statement}

The authors declare they have no competing interests.

\section{References}

$\longrightarrow 1$ Furukawa S, Fujita T, Shimabukuro M, Iwaki M, Yamada Y, Nakajima Y, Nakayama O, Makishima M, Matsuda $\mathrm{M}$, Shimomura I: Increased oxidative stress in obesity and its impact on metabolic syndrome. J Clin Invest 2004;114:1752-1761.

- Yu S, Allen JN, Dey A, Zhang L, Balandaram G, Kennett MJ, Xia M, Xiong N, Peters JM, Patterson A: The ron receptor tyrosine kinase regulates macrophage heterogeneity and plays a protective role in diet-induced obesity, atherosclerosis, and hepatosteatosis. J Immunol 2016;197:256.

-3 Ross MSCM, Poluhowich JJ: The effect of apple cider vinegar on adjuvant arthritic rats. Nutr Res 1984;4:737-741.

4 Ren H, Endo H, Watanbe E, Hayashi T: Chemical and sensory characteristics of chinese, korean, and japanese vinegars. J Tokyo Univ Fish 1997;84:1-11.

5 Aritsuka T, Tanaka K, Kiriyama S: Effect of beet fiber on lipid metabolism in rats fed a cholesterol-free diet in comparison with pectin and cellulose. Eiyo to Shokuryo 1989;42:295-304.

6 Hara H, Haga S, Y, Kiriyama S: Short-chain fatty acids suppress cholesterol synthesis in rat liver and intestine. J Nutr 1999;129:942-948.

7 Kondo T, Kishi M, Fushimi T, Kaga T: Acetic acid upregulates the expression of genes for fatty acid oxidation enzymes in liver to suppress body fat accumulation. J Agric Food Chem 2009;57:5982-5986.

-8 Sakakibara S, Yamauchi T, Oshima Y, Tsukamoto Y, Kadowaki T: Acetic acid activates hepatic ampk and reduces hyperglycemia in diabetic kk-a(y) mice. Biochem Biophys Res Commun 2006;344:597-604.

-9 Kahn BB, Alquier T, Carling D, Hardie DG: Amp-activated protein kinase: Ancient energy gauge provides clues to modern understanding of metabolism. Cell Metab 2005;1:15-25.

10 Lin L, Yang C, Xie Z, Zhang Y: A high-concentrate diet induced milk fat decline via glucagon-mediated activation of amp-activated protein kinase in dairy cows. Sci Rep 2017;7:44217.

-11 Kawaguchi T, Osatomi K, Yamashita H, Kabashima T, Uyeda K: Mechanism for fatty acid “sparing” effect on glucose-induced transcription regulation of carbohydrate-responsive element-binding protein by ampactivated protein kinase. J Biol Chem 2002;277:3829.

12 Iii GH, Mangum L: Exposure to bioaccumulative organochlorine compounds alters adipogenesis, fatty acid uptake, and adipokine production in nih3t3-11 cells. Toxicol In vitro 2011;25:394-402.

13 Fushimi T, Sato Y: Effect of acetic acid feeding on the circadian changes in glycogen and metabolites of glucose and lipid in liver and skeletal muscle of rats. Br J Nutr 2005;94:714-719. 


\section{Cellular Physiology Cell Physiol Biochem 2018;45:2021-2030 \begin{tabular}{l|l|l} 
and Biochemistry Published online: March 09, 2018 & $\begin{array}{l}\text { C) } 2018 \text { The Author(s). Published by S. Karger AG, Basel } \\
\text { www.karger.com/cpb }\end{array}$ \\
\hline
\end{tabular}}

14 Kerr JF, Wyllie AH, Currie AR: Apoptosis: A basic biological phenomenon with wide-ranging implications in tissue kinetics. Br J Cancer 1972;26:239.

15 Mehlem A, Hagberg CE, Muhl L, Eriksson U, Falkevall A: Imaging of neutral lipids by oil red o for analyzing the metabolic status in health and disease. Nat Protoc 2013;8:1149-1154.

-16 Sabater AG, Ribot J, Priego T, Vazquez I, Frank S, Palou A, Buchwald-Werner S: Consumption of a mango fruit powder protects mice from high-fat induced insulin resistance and hepatic fat accumulation. Cell Physiol Biochem 2017;42:564-578.

17 Andreelli F, Foretz M, Knauf C, Cani PD, Perrin C, Iglesias MA, Pillot B, Bado A, Tronche F, Mithieux G: Liver adenosine monophosphate-activated kinase-alpha2 catalytic subunit is a key target for the control of hepatic glucose production by adiponectin and leptin but not insulin. Endocrinology 2006;147:2432-2441.

18 Hardie DG: Amp-activated protein kinase: A master switch in glucose and lipid metabolism. Rev Endocr Metab Dis 2004;5:119-125.

19 Bronner M, Hertz R, Bar-Tana J: Kinase-independent transcriptional co-activation of peroxisome proliferator-activated receptor alpha by amp-activated protein kinase. Biochem J 2004;384:295-305.

20 Huang MQ Zhou CJ, Zhang YP, Zhang XQ Xu W, Lin J, Wang PJ: Salvianolic acid b ameliorates hyperglycemia and dyslipidemia in db/db mice through the ampk pathway. Cell Physiol Biochem 2016;40:933.

21 Sugden MC, Bulmer K, Gibbons GF, Knight BL, Holness MJ: Peroxisome-proliferator-activated receptoralpha (pparalpha) deficiency leads to dysregulation of hepatic lipid and carbohydrate metabolism by fatty acids and insulin. Biochem J 2002;364:361-368.

22 Huang H, Starodub O, Mcintosh A, Kier AB, Schroeder F: Liver fatty acid-binding protein targets fatty acids to the nucleus real time confocal and multiphoton fluorescence imaging in living cells. J Biol Chem 2002;277:29139-29151.

23 Lee K, Kerner J, Hoppel CL: Mitochondrial carnitine palmitoyltransferase 1a (cpt1a) is part of an outer membrane fatty acid transfer complex. J Biol Chem 2011;286:25655-25662.

24 Dobrzyn P, Dobrzyn A, Miyazaki M, Cohen P, Asilmaz E, Hardie DG, Friedman JM, Ntambi JM: Stearoyl-coa desaturase 1 deficiency increases fatty acid oxidation by activating amp-activated protein kinase in liver. Proc Natl Acad Sci USA 2004;101:6409.

25 Eaton S: Control of mitochondrial $\beta$-oxidation flux. Prog Lipid Res 2002;41:197-239.

-26 Djouadi F, Weinheimer CJ, Saffitz JE, Pitchford C, Bastin J, Gonzalez FJ, Kelly DP: A gender-related defect in lipid metabolism and glucose homeostasis in peroxisome proliferator- activated receptor alpha- deficient mice. J Clin Invest 1998;102:1083-1091.

27 Liu T, Yang LL, Zou L, Li DF, Wen HZ, Zheng PY, Xing LJ, Song HY, Tang XD, Ji G: Chinese medicine formula lingguizhugan decoction improves beta-oxidation and metabolism of fatty acid in high-fat-diet-induced rat model of fatty liver disease. Evid Based Complement Alternat Med 2013;2013:429738.

-28 Bojadžiev G: Pkb/akt induces transcription of enzymes involved in cholesterol and fatty acid biosynthesis via activation of srebp. Oncogene 2005;24:6465.

29 Zeng L, Tang W, Yin J, Feng L, Li Y, Yao X, Zhou B: Alisol a 24-acetate prevents hepatic steatosis and metabolic disorders in hepg2 cells. Cell Physiol Biochem 2016;40:453.

30 Wakil SJ, Stoops JK, Joshi VC: Fatty acid synthesis and its regulation. Annu Rev Biochem 1983;52:537.

-31 Postic C, Girard J: Contribution of de novo fatty acid synthesis to hepatic steatosis and insulin resistance: Lessons from genetically engineered mice. J Clin Invest 2008;118:829-838.

32 Tappy L, Lê KA: Metabolic effects of fructose and the worldwide increase in obesity. Physiol Rev 2010;90:23.

33 Deng Q, Liu G, Liu L, Zhang Y, Yin L, Shi X, Wang J, Yuan X, Sun G, Li Y: Bhba influences bovine hepatic lipid metabolism via ampk signaling pathway. J Cell Biochem 2015;116:1070. 